\title{
Weights of Heart Ventricles in Children with Hydrocephalus Treated with Ventriculo-caval Shunts
}

\author{
JOHN L. EMERY AND B. MAHGREFTE \\ From the Department of Pathology, Children's Hospital, Sheffield
}

The introduction of an effective valve system enabling the long-term shunting of cerebrospinal fluid from the cerebral ventricles into the right atrium of the heart was a turning point in the treatment of children with congenital hydrocephalus. It has transformed a mortality rate of about 80 per cent to a survival rate of approximately that figure.

Within months of the introduction of this treatment, thrombotic and embolic lesions were found in the lungs of children who were treated in this way and who did not survive (Anderson, 1959; Emery and Hilton, 1961). As pathologists became more alert to this complication, more thrombi were noted and, in the series recorded by Erdohazi, Eckstein, and Crome (1966) and Crome and Erdohazi (1966), the incidence was 53 per cent. In our series of approximately 300 cases, the impression gained is that if a child has had a shunt for a year, evidence of thromboembolism can always be found if sought with sufficient diligence.

Sperling et al. (1964) suggested that these thromboemboli could produce cor pulmonale, and this was supported by Erdohazi et al. (1966). We have, as yet, seen no death from chronic cor pulmonale in hydrocephalus treated with a shunt, though we have had several deaths from massive pulmonary thrombosis, nor have we seen evidence from an inspection of the pulmonary arteries in the lung that pulmonary hypertension had occurred. The possibility of gradual and insidious development of cor pulmonale, however, still causes unrest in the minds of physicians using this form of therapy. The present investigation was designed to obtain a provisional answer to this question, by attempting to find out if the right ventricle in children treated with ventriculo-caval shunts is hypertrophied. We have thus weighed the right and left ventricles in hearts from children with hydrocephalus with and

Received January 20, 1969. without shunts, and from a comparable group of normal children of the same age.

\section{SubJeCtS AND METHOdS}

Cases were selected from necropsies performed by the Department of Pathology at the Children's Hospital, Sheffield, during the period 1961 to 1968 . The ventricle weights were obtained by first dissecting the ventricles from the atria and great vessels, removing any gross fat present, cutting serial slices across both ventricles, and then dividing each slice through the ventricular septum. This method is described in a previous publication (Emery and Mithal, 1961), and the reasons for using this technique are described in that publication.

The cases were divided into two groups. (a) Hearts from children with hydrocephalus and with meningomyeloceles, who had no congenital heart deformity (119 cases): of these, 31 had had a ventriculo-caval shunt for periods ranging from 2 weeks to $6 \frac{1}{2}$ years, with a mean duration of 13.3 months. (b) 181 cases. Apparently completely normal hearts were accepted after excluding all children with the following conditions: spina bifida, hydrocephalus, or any other gross congenital malformation of the renal or any other tract, children with any cardiac or chronic pulmonary pathology or with cystic fibrosis of the pancreas, children with any evidence of hypertension or any known renal disease, and stillborns.

The ages of the two groups are summarized in Table I.

\section{RESULTS}

The weights of the cardiac ventricles were analysed by age and body weight, and related to the presence of hydrocephalus, with or without the presence of a shunt. The weight of the ventricles from normal children produced the same pattern as that seen in a previous study from this laboratory (Emery and Mithal, 1961), and the deviations from the mean were much smaller when the children were classified by body weight than by age. For that reason, the results related to hydrocephalus are presented relative to body weight. 
TABLE I

AGE PROPORTION IN BOTH GROUPS

\begin{tabular}{c|c|c|c|c|c|c}
\hline Group & $0-1$ wk. & $2-4$ wk. & $2-3$ mth. & $4-12$ mth. & $2-5$ yr. & Total \\
\hline A $\left\{\begin{array}{l}\text { With valve } \\
\text { Without valve }\end{array}\right.$ & -30 & 4 & 7 & 12 & 31 \\
\hline Total & 30 & 28 & 21 & 7 & 14 \\
\hline B Controls & 41 & 32 & 28 & 15 & 119 \\
\hline
\end{tabular}

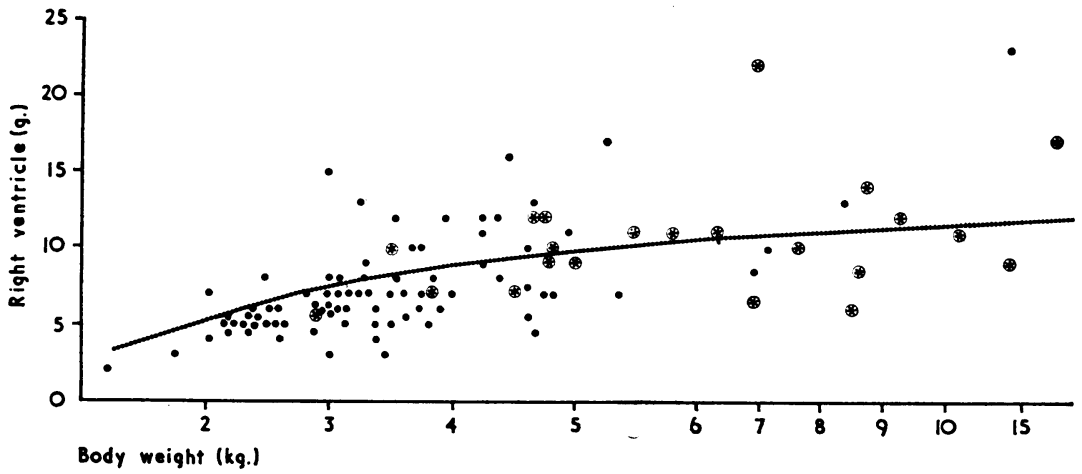

FIG.-The weights of the right ventricles from children with hydrocephalus associated with the Arnold Chiari deformity. The solid dots represent children who had not been treated with ventriculo-caval shunts. The wheels represent children who had been treated with ventriculo-caval shunts. The continuous dotted line represents the mean from normal children of the same body weight.

TABLE II

MEAN AND RATIO OF VENTRICULAR WEIGHTS RELATED TO BODY WEIGHT

\begin{tabular}{|c|c|c|c|c|c|c|c|c|}
\hline Body weight (kg.) & 2 & 3 & 4 & 5 & 6 & 7 & 8 & 10 \\
\hline $\begin{array}{c}\text { Hydrocephalics } \\
\text { Rt. ventricle } \\
\text { Lt. ventricle } \\
\text { Ratio } R / L\end{array}$ & $\begin{array}{l}5 \cdot 0 \\
4.7 \\
1.06\end{array}$ & $\begin{array}{l}6.3 \\
6.7 \\
0.94\end{array}$ & $\begin{array}{l}8.4 \\
9 \cdot 7 \\
0.86\end{array}$ & $\begin{array}{c}9.5 \\
12 \cdot 3 \\
0.77\end{array}$ & $\begin{array}{c}10 \cdot 3 \\
14 \cdot 6 \\
0.70\end{array}$ & $\begin{array}{c}10.7 \\
15.8 \\
0.68\end{array}$ & $\begin{array}{c}11.0 \\
17.2 \\
0.63\end{array}$ & $\begin{array}{c}11.2 \\
17.4 \\
0.64\end{array}$ \\
\hline $\begin{array}{l}\text { Controls } \\
\text { Rt. ventricle } \\
\text { Lt. ventricle } \\
\text { Ratio } R / L\end{array}$ & $\begin{array}{l}5 \cdot 2 \\
4 \cdot 7 \\
1 \cdot 10\end{array}$ & $\begin{array}{l}7 \cdot 2 \\
7.5 \\
0.96\end{array}$ & $\begin{array}{c}8 \cdot 7 \\
10 \cdot 7 \\
0 \cdot 81\end{array}$ & $\begin{array}{c}9.7 \\
13.8 \\
0.70\end{array}$ & $\begin{array}{c}10.4 \\
16.0 \\
0.65\end{array}$ & $\begin{array}{c}10.7 \\
16.6 \\
0.64\end{array}$ & $\begin{array}{c}11.0 \\
18.0 \\
0.61\end{array}$ & $\begin{array}{c}11.2 \\
18.2 \\
0.61\end{array}$ \\
\hline
\end{tabular}

The weights of the left and right ventricles, related to body weight, are given in Table II, and in the Fig. the weights of the right ventricles from children with hydrocephalus with and without cerebro-cardiac shunts are shown, together with the mean line from normal children.

Statistical analysis confirms the visual impression given by the Fig., that the weights of the right ventricles from the children with cerebro-cardiac shunts show no increase compared with normal controls. The weight of the untreated (non-shunted) child with hydrocephalus also showed no significant difference from normal in the children over $3 \mathrm{~kg}$. Below this body weight, the ventricle weights are, if anything, slightly reduced, but this is not statistically significant. When the ventricle weights were analysed against postnatal age, no difference was found between the child with a shunt and the child with hydrocephalus without a shunt. The weights of the hearts were lower on an age basis in both right and left ventricles than the normal, and this is due to the hydrocephalic children being generally stunted.

\section{Discussion}

From the cardiac muscle weights found in this 
study, it appears that the heart ventricles grow similarly in children with hydrocephalus and in normal children, and that the presence of a cerebro-cardiac shunt, though presenting frequent embolic/thrombotic lesions in the lungs, does not appear, at least over a period of a few (less than five) years, to induce changes in the heart suggesting the development of significant pulmonary hypertension.

The postnatal changes in weight of the ventricles in this study show the accelerated increase in growth of the left heart after birth as in our own previous study (Emery and Mithal, 1961) and in the older literature (Müller, 1883; Falk, 1901) and in dogs (Latimer, 1965). The apparent actual diminution in weight of the right ventricle suggested by Keen (1955) and Recavarren and Arias-Stella (1964) is probably due to an unfortunate selection of material and method of study. The present study does not rest on any factors dependent on the method of weighing hearts, as all cases, whether normal or hydrocephalic, treated or untreated, were handled in the same way. Thus, the groups form controls for each other.

This study does not exclude the eventual development of pulmonary hypertension in some children treated with cerebro-caval shunts, but in view of the number of cases in this unit we would have expected to have found some cases by this time if that complication were likely to have been of any great clinical importance. The cerebro-caval shunt is by no means without danger, and we have seen many other cardio-pulmonary complications arising from it, including perforation of the atrium, endocarditis, the production of massive ball thrombi in the right atrium, massive lethal pulmonary embolism, and pulmonary haemosiderosis.

\section{SUMMARY}

A study of the weights of the right ventricle from
119 children with hydrocephalus has shown that in those having a cerebro-caval shunt for an average of 13 months ( 2 weeks to 6 years), there was no increase in weight suggesting the onset of incipient pulmonary hypertension.

The weights of the left and right ventricles are the same, when related to the total body weight, in children with hydrocephalus as the weights in normal children.

\section{REFERENCES}

Anderson, F. M. (1959). Ventriculo-auriculostomy in treatment of hydrocephalics. $\mathcal{F}$. Neurosurg., 16, 551 .

Crome, L., and Erdohazi, M. (1966). Main pathological findings in hydrocephalic children treated by ventricularatrial shunt. Arch. Dis. Childh., 41, 179.

Emery, J. L., and Hilton, H. B. (1961). Lung and heart complications of the treatment of hydrocephalus by ventriculoauriculostomy. Surgery, 50, 309.

—, and Mithal, A. (1961). Weights of cardiac ventricles at and after birth. Brit. Heart f., 23, 313.

Erdohazi, M., Eckstein, H. B., and Crome, L. (1966). Pulmonary embolisation as a complication of ventriculoatrial shunts inserted for hydrocephalus. In Hydrocephalus and Spina Bifida. Develop. Med. Child Neurol., Suppl. 11, p. 36.

Falk, A. (1901). The growth of the heart in children according to age. Dissertation, St. Petersburg. (Cited by Latimer, 1965.) [In Russian.]

Keen, E. N. (1955). The postnatal development of the human cardiac ventricles. F. Anat. (Lond.), 89, 484.

Latimer, H. B. (1965). The weight and thickness of the two ventricular walls in the newborn dog heart. Anat. Rec., $152,225$.

Müller, W. (1883). Die Massenverhältnisse des menschlichen Herzens. Leopold Voss, Hamburg and Leipzig.

Recavarren, S., and Arias-Stella, J. (1964). Growth and development of the ventricular myocardium from birth to adult life. Brit. Heart f., 26, 187.

Sperling, D. R., Patrick, J. R., Anderson, F., and Fyler, D. C. (1964). Cor pulmonale secondary to ventriculoauriculostomy. Amer. F. Dis. Child., 107, 308. 